\title{
PENGARUH PENAMBAHAN BATU KARANG SEBAGAI SUBSTITUSI AGREGAT HALUS DALAMPEMBUATAN PAVING BLOCK
}

\author{
Edy Gardjito ${ }^{1}$, Agata Iwan Candra ${ }^{2}$, Yosef Cahyo
}

${ }^{1,2,3}$ Sipil Fakultas Teknik Universitas Kadiri

e-mail :*1edygardjito@unik-kediri.ac.id,iwan_candra@unikkediri.ac.id,Yosef.cs@unikkediri.ac.id

\begin{abstract}
Material exploitation, especially the use of sand as the main component of concrete, needs to be reduced. The purpose of this research is to find out the value of compressive strength from the addition of rocks to achieve compressive strength according to the standard mix design of paving blocks. This research was conducted at the University's Civil Engineering Laboratory. Attending a trial and error method, the samples tested were cube with a size of $15 \times 15 \times 15 \mathrm{~cm}$ with 3 pieces with the quality of paving planned and K-225 or $18.675 \mathrm{MPa}$. The method of making specimens includes semimechanics using a concrete mixer. Fractional waste The rock is crushed into small pieces and then put in messin abrassion to get smaller pieces of rock and become grains of sand. Test result obtained a percentage of $25 \%$ indicating a compressive strength of $22.1 \mathrm{MPa}, 20.3 \mathrm{MPa}, 19.9 \mathrm{MPa}$, and has an average value of $21.8 \mathrm{MPa}$. Then the results from the substitution experience $i$ increase against compressive strength.
\end{abstract}

Keywords: Coral, Fine Aggregate, Compressive Strength.

\section{Abstrak}

Eksploitasi material, terutama penggunaan pasir sebagai komponen utama beton, perlu dikurangi. Tujuan dari penelitian ini adalah untuk mengetahui nilai kekuatan tekan dari penambahan batuan untuk mencapai kekuatan tekan sesuai dengan desain campuran standar balok paving. Penelitian ini dilakukan di Laboratorium Teknik Sipil Universitas. Menghadiri metode coba-coba, sampel yang diuji adalah kubus dengan ukuran $15 \times 15 \times 15 \mathrm{~cm}$ dengan 3 buah dengan kualitas paving yang direncanakan dan $\mathrm{K}$ 225 atau 18,675 MPa. Metode pembuatan spesimen termasuk semi-mekanika menggunakan mixer beton. Limbah pecahan Batuan dihancurkan menjadi potongan-potongan kecil dan kemudian dimasukkan ke dalam abrasi untuk mendapatkan potongan batu yang lebih kecil dan menjadi butiran pasir. Hasil pengujian diperoleh persentase 25\% yang menunjukkan kekuatan tekan 22,1 MPa, 20,3 MPa, 19,9MPa, dan memiliki nilai rata-rata 21,8 MPa. Kemudian hasil dari pengalaman substitusi saya meningkat terhadap kekuatan tekan

Kata Kunci: Karang, Agregat Halus, Kekuatan Kompresif.

\section{PENDAHULUAN}

\subsection{Tinjauan Umum}

Pengerasan jalan umumnya menggunakan media aspal. Namun, saat ini sering terlihat pengerasan jalan dengan media selain aspal yaitu paving block.Paving block atau bata beton untuk lantai merupakan salah satu batu cetak yang sudah dikenal dimasyarakat dan banyak 
digunakansebagai bahan bangunan gedung dan jalan. Bahan dasar paving block yaitusemen portland, air, agregat halus, dan agregat kasar.

Inovasi yang dilakukan yaitu batu karang sebagai substitusi agregat halus dalam pembuatan paving blockdalam hal ini kedepannya dapat dimanfaatkan warga didaerah pesisir pantai untuk menabah mata pencaharian warga setempat pesisir pantai. Adapun alternatif bahan yang digunakan pada penelitian ini berbahan dasar batu karang yang dihaluskan agar seperti butiran pasir.

\section{2rumusan Masalah}

Berdasarkan permasalahan diatas maka dapat disimpulkan dalam rumusan masalah sebagai berikut :

Berapa kuat tekan yang dihasilkan dari penambahan batu karang sebagai substitusi agregat halus pada paving blok?

\section{3tinjauan Pustaka}

\subsubsection{Beton}

Beton merupakan salah satu bahan konstruksi yang telah digunakan untuk bangunan gedung, jembatan, jalan, dan lain-lain. Bahan campuran Beton melainkan agregat halus, agregat kasar, semen portland atau semen merek lain, dan air, ada beberapa yang menggunakan bahan tambahan (aditif) sampai menjadi satu kesatuan yang homogen.

\subsubsection{Paving Block}

Paving block adalah suatu benda yang terbuat dari campuran semen, agregat halus, agregat kasar dan air yang mengeras dengan bentuk dan mutu yang sudah ditentukan. Keunggulan paving block adalah menjaga keseimbangan air tanah, serta menjadi serapan air yang baik.

\subsubsection{Kuat Tekan}

Kuat tekan adalah sifat kemampuan menahan atau memikul suatu beban tekan. Kuat tekan dipengaruhi oleh komposisi mineral utama. C3S memberikan kontribusi yang besar pada perkembangan kuat tekan awal, sedangkan C2S memberikan kekuatan semen pada umur yang lebih lama. Apabila C3S dan C2S bereaksi dengan air kembali membentuk senyawa CSH dan $\mathrm{Ca}(\mathrm{OH}) 2$. Berdasarkan (BSN 2011) kuat tekan beton dapat diyatakan dengan persamaan:

$$
\mathbf{f c}^{\prime}=\mathbf{P} / \mathbf{A}
$$

Dimana :

$\mathrm{fc}^{\prime}=$ Nilai kuat tekan beton

(MPa) $\mathrm{P}=$ Beban maksimum $(\mathrm{KN})$

(N) A = Luas penampang benda uji $\left(\mathrm{cm}^{2}\right)$ 


\section{METODE PENELITIAN}

\subsection{Material}

\subsubsection{Agregat kasar}

Batu split (batu koral) adalah salah satu jenis batu material bangunan yang di peroleh dengan cara membelah atau memecah batu yang berukuran besar menjadi kecil. Batu split juga sering disebut dengan nama batu belah.

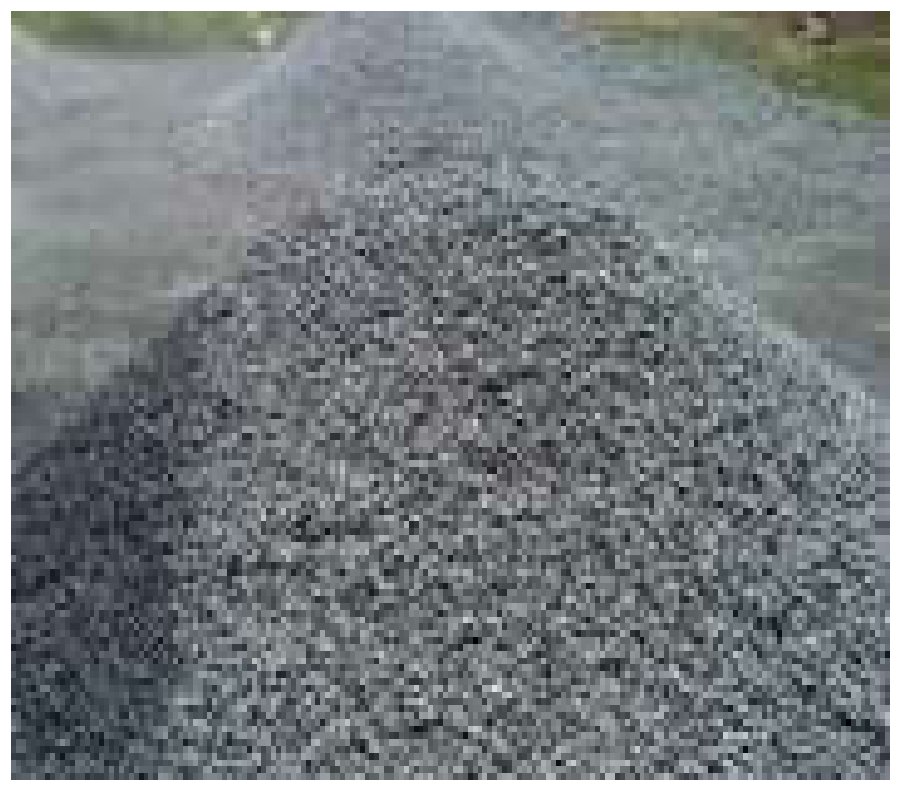

Gambar 1. Batu pecah

\subsubsection{Semen}

Semen merupakan senyawa atau zat pengikat hidrolis yang terdiri dari senyawa C-S-H (kalsium silikat hidrat) yang apabila bereaksi dengan air akan dapat mengikat bahanbahan padat lainnya membentuk satu kesatuan yang kompak, padat dan keras. Fungsi semen adalah untuk mengisi rongga-rongga diantara butiran agregat agar terjadi suatu massa yang kompak atau padat. 


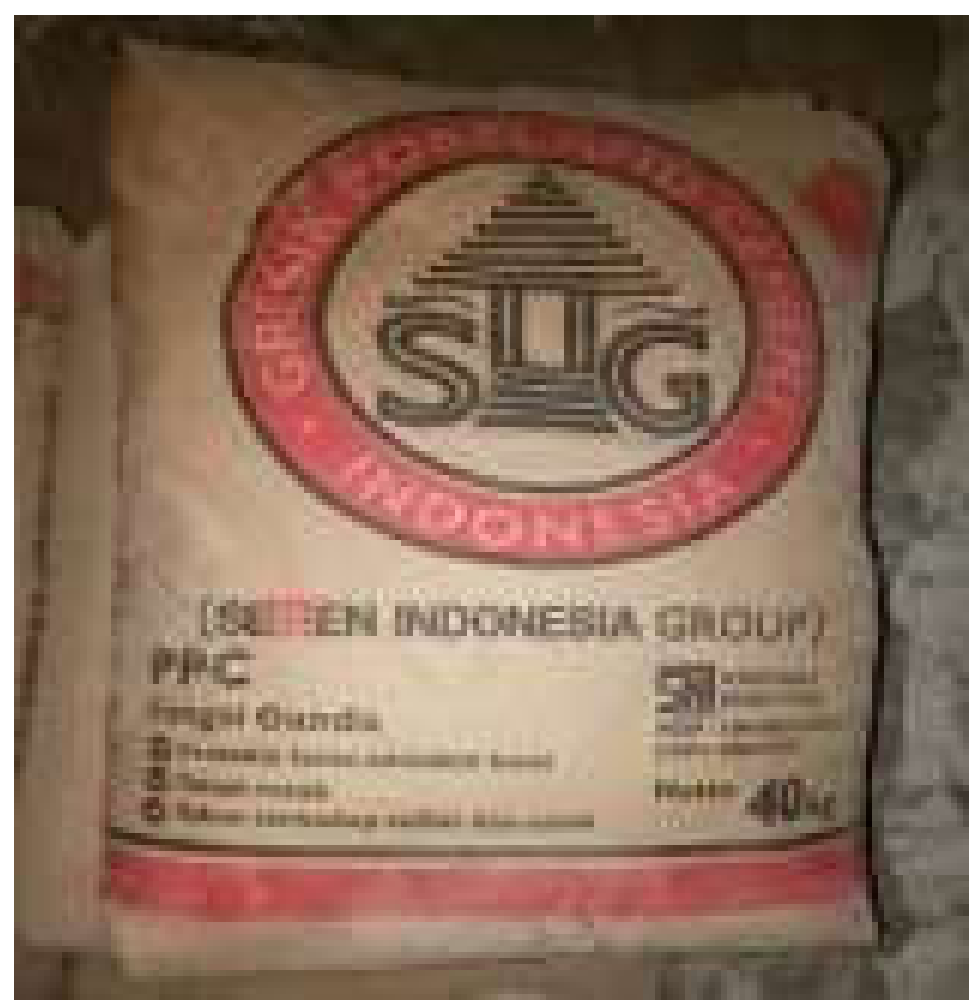

Gambar 2. Semen Portland (PC)

\subsubsection{Pasir}

Pasir adalah salah satu jenis agragat yang dibutuhkan untuk bahan pembuatan beton yang berukuran mulai dari 0,0625 hingga $2 \mathrm{~mm}$. Pasir terbentuk karena adanya proses pelapukan fisik dan kimia pada batuan.

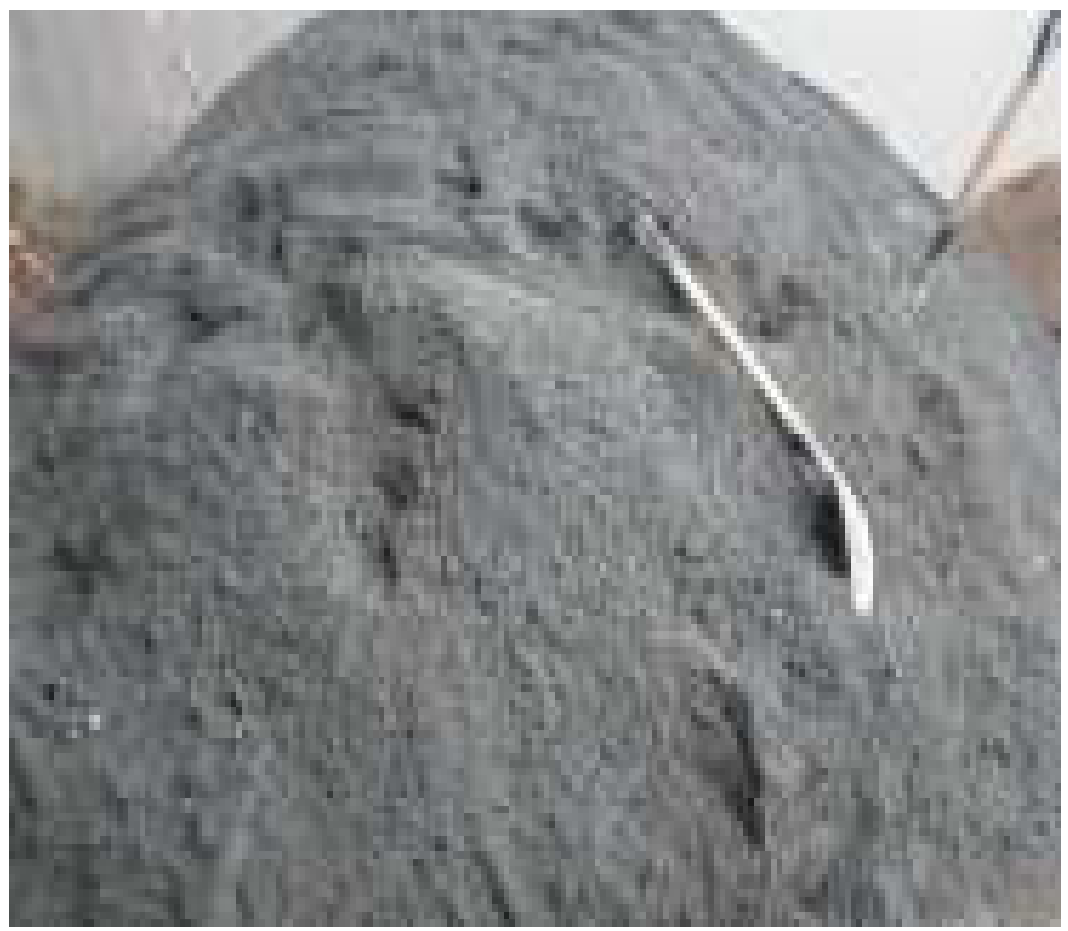


Gambar 3. Pasir Gunung Gedang Blitar

\subsubsection{Air}

Air merupakan zat cair yang terdiri dari senyawa hidrogen $(\mathrm{H} 2 \mathrm{O})$ dan oksigen $(\mathrm{O})$ kemudian menjadi air murni yang memiliki rumus kimia $\mathrm{H} 2 \mathrm{O}$.

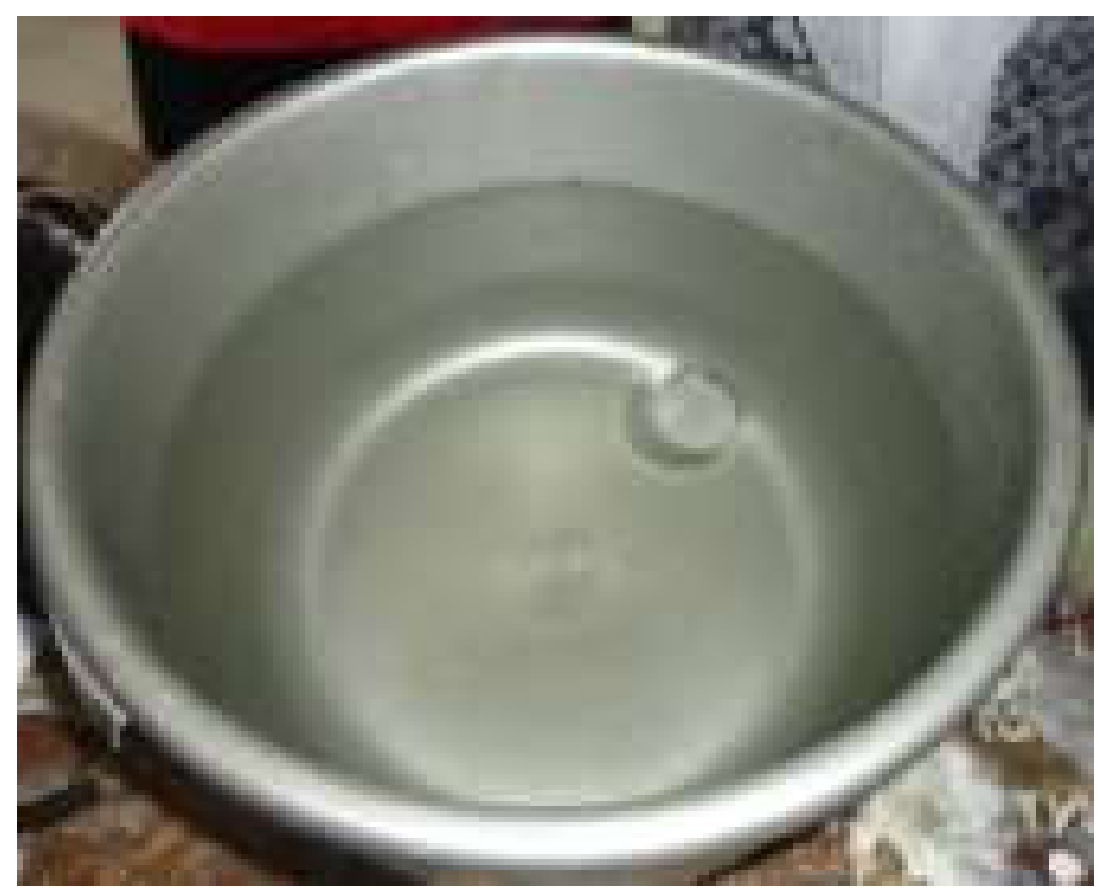

Gambar 4. Air bersih

\subsubsection{Batu karang}

Karang adalahkumpulan dari fosil binatang laut yang sangat kecil atau kumpulan dari polip laut yang sangat kecil yang mengeluarkan semacam zat kapur yang membentuk suatu atau beberapa gundukan yang besar ataupun yang berukuran sedang. 


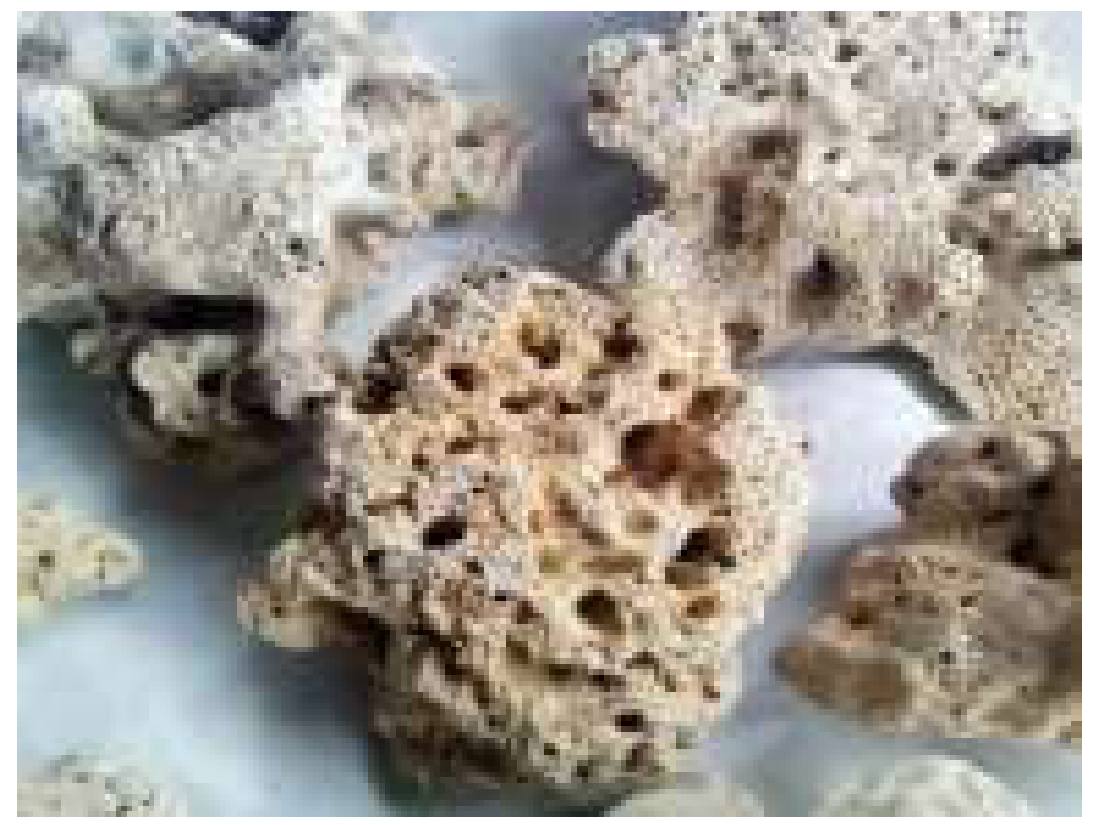

Gambar 5. Limbah Pecahan Batu Krang

\subsection{Langkah kerja}

Metode langkah kerja untuk 3 sampel analisis REKAYASA JOB MIX BETON pada paving block antara lain :

a. Proses pengambilan pasir menggunakan ayakan lolos berdiameter $0,40 \mathrm{~mm}$ dan tertahan pada ayakan berdiameter 0,39 .

b. Pengovenan Pasir guna pengambilan bahan sesuai berat kering sebanyak $6,16875 \mathrm{~kg}$ (berat normal dikurangi 25\% dan diganti pasir dari batu karang).

c. Menyediakan Agregat kasar dengan lolos ayakan no. $1^{1 / 2}$ ( $\left.37,5 \mathrm{~mm}\right)$, tertahan ayakan no. 1" ( $25,4 \mathrm{~mm})$ dan sebanyak $12,355 \mathrm{~kg}$.

d. Menyiapkan Semen Portland sebanyak 4,375 kg.

e. Menyiapkan Air guna proses pelarutan dan pencampuran sebanyak 2,555 kg.

f. Menyiapkan batu karang yang telah dihaluskan sebagai subtitusi agregat halus sebanyak $2,057 \mathrm{~kg}$ ( $25 \%$ dari pasir),lolos ayakan no 40 tertahan no 50 dan lolos ayakan no 50 tertahan no 100 .

g. Proses mixing menggunakan media mesin pengaduk elektrik.

1) Masukan air dan semen kedalam mesin pengaduk.

2) Putar mesin pengaduk selama 20 menit agar bahan perekat tercampur dengan sempurna.

3) Masukan seluruh agregat kasar pada mesin pengaduk secara bertahap.

4) Setelah agregat kasar dikira telah tercampur dengan campuran air dan semen pada 15 menit putaran Mixer, masukkan Pasir dan batu karang yang telah di haluskan secara bertahap. 
5) Setelah seluruh bahan tercampur secara sempurna, adonan di uji test slump guna mengetahui kadar air yang terkandung pada adonan segar beton.

6) Jika kadar air setabil masukan adonan segar mix design beton kedalam cetakan kubus dengan ukuran sisi $15 \mathrm{~cm}$ serta dalam pemasukkan adonan beton segar kedalam cetakan diharuskan untuk disertai penggetaran pada cetakan guna mengantisipasi rongga pada struktur beton.

7) Biarkan adonan Beton mengering hingga sempurna, antara 7 - 10 Hari.

8) Setelah kering, bongkar cetakan beton dan lanjutkan proses curing beton kedalam kolam selama waktu analisa 28 hari.

9) Angkat Beton dari kolam curing dan angin-anginkan Beton selama 1 hari guna proses pengeringan.

10) Proses test uji kuat tekan beton.

\section{HASIL DAN PEMBAHASAN}

Dalam hal ini penujian kuat tekan pada sempel dilaksanakan setelah uji curing dengan umur 28 hari. Tujuan dari pengujian kuat tekan pada sempel adalah untuk mengetahui kuat tekan yang dihasilkan dari penambahan batu karang substitusi agreat halus pada paving block,untuk penambahan batu karang dengan prosentase $25 \%$ dari agregat halus normal. perbandingan hasil dari penambahan batu karang tersebut menggunakan perbandingan dengan paving block normalyang memiliki mutu K-225 atau 18,675 MPa.

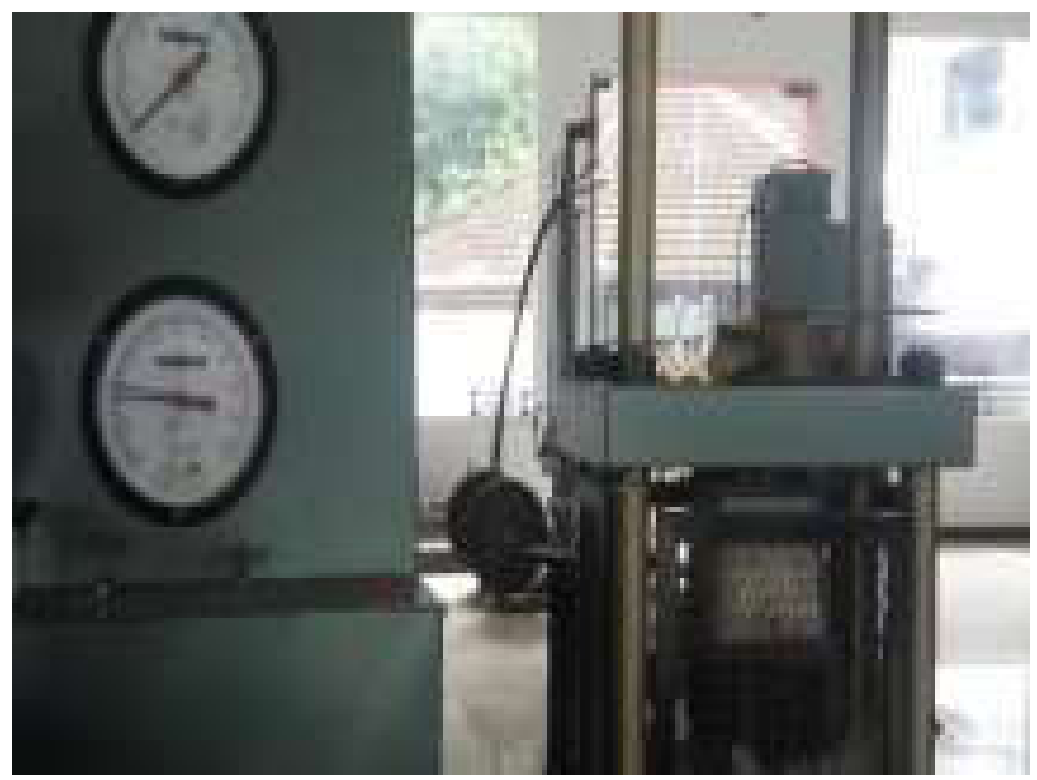

Gambar 6. Pengujian Kuat Tekan

Dilihat dari uji kuat tekan pada sempel yang berumur 28 hari mengalami peningkatan kuat tekan dan mengkasilkan kuat tekan sebesar 22,1 MPa, 20,3 MPa, 19,9 MPa pada sempel 
penambahan batu karang sebagai subtitusi agregat halus. Dilihat dari hasil nilai kuat tekan tersebut maka di dapat nilai rata-rata sebesar 21,8 MPa.

\section{KESIMPULAN dan SARAN}

Kesimpulan

Berdasarkan penelitian tentang pengaruh penambahan batu karang sebagai substitusi agreagat halus dalam pembuatan paving block yang telah dilakukan dan hasil analisa data yangtelah didapatkan bahwa Hasil pengujian kuat tekan dengan prosentase $25 \%$ dari agregat halus normal mengalami peningkatan nilai kuat tekan yang dihasilkan sebesar 22,1 $\mathrm{MPa}, 20,3 \mathrm{MPa}$, 19,9 MPadanmendapat niilai rata-rata sebesar 21,8 MPa.

Saran

Berdasarkan hasil kesimpulan diatas, maka penulis memberikan saran yang sekiranya dapat dipertimbangkan, yaitu :

1. Perlunya pemanfaatan dari limbah pecahan batu karang atau batu karang yang sudah mati tidak di tumbuhi makhluk laut yang berada di pesisir pantai untuk digunakan sebagai campuran paving block. Hal ini bertujuan agar batu karang tersebut memiliki nilai jual dan dapat di manfaatkan sebagai sumber mata pencaharian warga pesisir pantai.

2. Perlu dilakukannya penelitian lebih lanjut guna memperoleh hasil yang maksimal terhadap pemakaian limbah pecahan batu karang sebagai agregat subtitusi.

3. Untuk penelitian selanjutnya yang terkait dengan pemanfaatan limbah pecahan batu karang, agar menghitung rencana anggaran biaya (RAB)agar mendapat hasil yang lebih baik dengan kegunaan seperti paving pada jalan perumahan dan area taman.

\section{DAFTAR PUSTAKA}

[1] Antono, A, 1995, Bahan Konstruksi Teknik Sipil, Universitas Atma Jaya, Yogyakarta.

[2] Antono, A, 1995, Teknologi Beton. Universitas Atma Jaya, Yogyakarta.

[3] Dimitrioglou, N, 2015. "Production and Characterization of Concrete Paving Blocks Containing Ferronickel Slag as a Substitute for Aggregates." Waste and Biomass Valorization. Springer Netherlands.

[4] Departemen Pekerjaan Umum, 2002, Tata Cara Perhitungan Struktur BetonUntuk Bangunan Gedung dengan Standar SK SNI 032487-2002, BadanStandarisasi Nasional.

[5] Departemen Pekerjaan Umum, 2008, Cara Uji Berat Isi Beton Ringan 
Struktural SNI 3402-2008, Badan Standarisasi Nasional

[6] Departemen Pekerjaan Umum, 2013, Tata Cara Perhitungan Struktur BetonUntuk

Bangunan Gedung dengan Standar SK SNI 03-2487-2013,

BadanStandarisasi Nasional

[7] JIS A 1148, 2010, Method of Test for Resistance of Concrete to Freeze andThawing, Japan Concrete Institute.

[8] https://sanpaving.wordpress.com/paving-block-atau-conblock-pengertian-jenis danklarifikasi.

[9] Hunggurami, E. (2017) „Perbandingan Desain Campuran Beton Normal

Menggunakan Sni 03-2834-2000 Dan Sni 7656: 2012", VI(2), pp. 165-172.

[10] Murdock, L. J., dkk 1986, Bahan Dan Praktek Beton, Erlangga, Jakarta.

[11] SNI 03-0691-1996. 1996. Bata Beton. Jakarta: Badan Standarisasi Nasional.

[12] Tjokrodimulyo, Kardiyono, 1992, TEKNOLOGI BETON, Buku Ajar Jurusan Teknik Sipil Fakultas Teknik UGM, Yogyakarta.

[13] Tjokrodimuljo, K. 1996. Teknologi Beton. Yogyakarta : Andi.

[14] Bintang, A. P., Setyanto, S., \& Adha, I. (2016). Studi Pengaruh Penambahan Bahan Additive TX-300 Terhadap Kuat Tekan Batu Bata Pasca Pembakaran. Jurnal Rekayasa Sipil dan Desain, 3(3), 381-390.

[15] SNI 2493:2011, Tata cara pembuatan dan perawatan benda uji di laboraturium 